\title{
FORMAÇÃO DOCENTE PARA O USO DA TECNOLOGIAASSISTIVA NA EDUCAÇÃO INFANTIL
}

\section{TEACHER TRAINING FOR THE USE OF ASSISTIVE TECHNOLOGY IN CHILDHOOD EDUCATION}

\author{
Me. Simone de Oliveira de Emer, Universidade Federal do Rio Grande do Sul-UFRGS, \\ simone.emer@gmail.com
}

Esp. Jocimara de Lima Mauer, Faculdade da Serra Gaúcha -FSG, jocimara_mauer@hotmail.com Esp. Luciana Batecini, Faculdade da Serra Gaúcha -FSG, bateciniluciana@gmail.com

Resumo: O presente trabalho tem como objetivo promover a formação docente para o uso da Tecnologia Assistiva em alunos com deficiência na educação infantil. Na medida em que as tecnologias digitais vão invadindo o nosso dia a dia, torna-se imprescindível o uso de recursos tecnológicos nos projetos pedagógicos da escola, no qual o professor possa transformar a informação obtida em formação aos seus alunos, oportunizando o acesso à Tecnologia Assistiva e proporcionando a inclusão. Como método de pesquisa, foi utilizada a pesquisa exploratória e quanto ao procedimento, o estudo de caso, com abordagem qualitativa. Para a coleta de dados utilizou-se a observação participante e para a interpretação dos dados, foi aplicada a análise de conteúdo. Foi possível observar que os professores têm consciência da importância dos avanços tecnológicos na área da educação, porém, lhes faltam formação e incentivo para a utilização correta desses recursos. Já o uso da tecnologia assistiva, ainda aparece como uma realidade distante de nossas escolas, uma das causas pode ser a falta de preparo para acolhê-los.

Palavras-Chave: Formação Docente. Tecnologia Assistiva. Deficiência. Inclusão

Abstract: The present work aims to promote teacher training for the use of Assistive Technology in students with disabilities in early childhood education. In the extent that digital technologies are invading our daily lives, it is essential the use of technological resources in educational projects of the school in which the teacher can transform the information obtained in training their students, providing opportunities for access to assistive technology and providing inclusion. As a research method, exploratory research was utilized and as the procedure, the case study with a qualitative approach was used. To collect data it was used participant observation and for the interpretation of data, content analysis. It was possible to observe that teachers are aware of the importance of technological advances in education, but they lack training and incentives for the proper use of these resources, since the use of assistive technology still appears as a reality out of our schools, one of the causes may be the lack of preparation to welcome them.

Keywords: Teacher Training. Assistive Technology. Disability. Inclusion.

\section{INTRODUÇÃO}

A organização Mundial de Saúde (OMS) estima que existam, no mundo inteiro, mais de 600 milhões de pessoas com deficiência, ou seja, cerca de $10 \%$ da população mundial. Essa estatística nos promove uma compreensão maior do nosso desafio de construir uma sociedade inclusiva, pois como afirma Vygotsky (1988), a situação que marca a vida do aluno com deficiência não é a própria deficiência, mas sim, as consequências sociais que dela 
acarretam. Nesse sentido percebemos a importância de construir projetos pedagógicos inclusivos nas escolas, e que possibilitem o acesso de ferramentas classificadas como Tecnologia Assistiva.

Percebe-se também a necessidade de integração das tecnologias digitais aos projetos pedagógicos. Na medida em que os professores acreditam na construção e não na transferência do conhecimento. Observam-se os benefícios oriundos do uso da tecnologia na educação, principalmente em relação às habilidades cognitivas dos alunos que a utilizam (SIQUEIRA, 2007). Cabe ressaltar que esse processo exige que a escola esteja preparada para aceitar os recursos tecnológicos com os recursos e materiais necessários, uma vez que, as tecnologias já estão presentes em todas as esferas da vida social.

Nesse contexto, percebe-se a importância da formação docente continuada, pois pouco ajudaria ter acesso às tecnologias digitais se os educadores não estiverem preparados para a sua correta utilização. Essa pesquisa tem como objetivo promover a formação docente para o uso da tecnologia assistiva em alunos com deficiência na educação infantil, uma vez que, o acesso a essas crianças nas escolas regulares é uma realidade e assim como essa afirmação, é também o despreparo das escolas e professores para atender a demanda.

Para a realização desse trabalho, utilizou-se a pesquisa exploratória, no qual houve o estudo aprofundado sobre o tema escolhido. O procedimento metodológico empregado foi o estudo de caso com abordagem qualitativa, pois teve como objetivo examinar e descrever comportamento de variáveis. Para a técnica de coleta de dados foi escolhida a observação participante e para a interpretação dos dados, foi aplicada a análise de conteúdo.

A estruturação desse artigo apresenta-se na seguinte ordem: a primeira parte consiste na Introdução, com as ideias principais do tema abordado. A segunda parte Fundamentação Teórica, expõe a opinião de diversos autores no que se refere à formação docente, tecnologia assistiva e inclusão. A terceira parte Procedimentos Metodológicos, apresenta os tipos de pesquisas utilizados. A quarta parte, Apresentação e Análise dos Resultados, consistem no resultado da pesquisa. E a quinta parte Considerações Finais a sobre a pesquisa.

\section{OS AVANÇOS TECNOLÓGICOS}

\subsection{Formação docente}

O desenvolvimento profissional dos educadores inicia primeiramente no curso de formação inicial, no qual passam a contrastar seus conhecimentos teóricos com a prática por meio dos estágios supervisionados, mas seu desenvolvimento ocorrerá efetivamente, no exercício de sua profissão. Conforme afirma Libâneo (2001), o professor produz sua profissionalidade no exercício do trabalho, e esta é a ideia chave do conceito de formação continuada.

Nessa perspectiva a escola aparece como um local de aprendizagem do professor, no qual, poderá desenvolver os saberes e as competências do ensinar, colocando em prática seus conhecimentos e habilidades diante das diferentes situações do contexto escolar. O professor se forma com os demais colegas a equipe de trabalho, no qual compartilham sua profissão e seus problemas, aprendendo assim novos saberes e agindo de modo coletivo.

Para Rangel (2011), a formação do educador deve ter em sua prática a democratização do conhecimento, permitindo uma posição crítica, reflexiva e transformadora, não só individual, mas também coletivamente, na busca de garantir os direitos de todos os indivíduos.

Na explicação de Vygotsky (1988), no qual o ser humano é um ser social e o seu desenvolvimento se dá na participação do meio em que está inserido, podemos refletir sobre os dias atuais. Em que os avanços tecnológicos já fazem parte da vida da maioria das pessoas, 
seja no trabalho, no lazer e nos processos educativos. A partir da análise sugerida, percebe-se a importância das tecnologias digitais nas práticas pedagógicas apresentando uma nova proposta para os alunos dessa nova geração.

Demo (2004) ressalta que o uso da tecnologia digital deve ser entendido como uma ferramenta de representação do conhecimento, no qual o grande desafio são professores que saibam transformar a informação obtida em formação aos seus alunos.

O professor precisa aprender a utilizar as ferramentas digitais, não apenas por ser uma necessidade do mundo contemporâneo, mas para dar significado para elas na visão do aluno e para que não dissocie o conhecimento da realidade (EMER, 2011).

Por isso, a formação docente é de extrema relevância para que o professor esteja preparado no processo de mediar o aluno a novos mundos e descobertas do saber, como sujeitos pensantes, capazes de refletir e agir criticamente diante dos desafios pessoais e profissionais (EMER, 2011). Nesse contexto, cabe refletir o papel do educador na dinâmica escolar, e de que forma irá utilizar esses aparatos tecnológicos, considerando que as escolhas das tecnologias digitais devem ser de acordo com as necessidades e realidade de cada escola e de seus alunos.

\subsection{Tecnologia assistiva}

Tecnologia Assistiva (TA), também conhecida como Tecnologia Adaptativa ou Ajudas Técnicas é um termo utilizado para denominar um conjunto de recursos que contribuem para proporcionar às Pessoas com Necessidades Educativas Especiais (PNEEs) maior independência, autonomia, qualidade de vida e inclusão na vida social (HOGETOP; SANTAROSA, 2002).

Como afirma Bersch (2008), a Tecnologia Assistiva é apresentada como um auxílio que tem como objetivo promover a ampliação de uma habilidade funcional deficitária ou possibilitar a realização de uma função que se encontra impedida por circunstância de deficiência ou pelo envelhecimento. Portanto, as Tecnologias Assistivas são desde recursos simples e de baixo custo que podem ser utilizados em sala de aula, conforme as especificações de cada aluno com necessidades especiais, até sofisticados programas especiais de computadores que visam à acessibilidade.

Para Emer (2011), antes de ser considerada a nomenclatura brasileira de Tecnologia Assistiva, em 2006, a Secretaria de Educação Especial/MEC publicou o documento Sala de Recursos Multifuncionais, num espaço de Atendimento Educacional Especializado, dedicados à prática da Tecnologia Assistiva, com o objetivo de auxiliar na inclusão de alunos com deficiência na escola comum.

O mais importante aspecto a ser considerado na escolha de uma Tecnologia Assistiva é analisar as reais condições e as características do usuário que irá utilizar, portanto, é necessário avaliar as potencialidades de cada aluno diante da utilização de uma determinada ferramenta ou recurso para que ele possa ser realmente usado para melhorar suas habilidades e o seu processo de inclusão na sociedade (HOGETOP; SANTAROSA, 2002).

\subsection{Inclusão}

Na sociedade contemporânea é difícil falarmos em Tecnologia Assistiva sem falarmos de inclusão, pois nos dias atuais, presenciamos a implantação de políticas educativas, visando contemplar uma democratização de ensino diferenciado, com a ampliação de oportunidades de escolarização para todos os cidadãos, independente de suas diferenças e condições especiais (SANTOS, ARAÚJO, 2011 apud RANGEL, 2011). 
As autoras concretizam esse contexto na atual Lei de Diretrizes e Bases da Educação Nacional (LDB n9.394/96) ao tratar a Educação Especial como uma modalidade de educação escolar voltada para a formação do indivíduo, que deve se realizar transversalmente, permeando todos os níveis e as demais modalidades de ensino nas instituições escolares. Por Educação Inclusiva, segundo a LDB, se entende o processo de inclusão das PNEEs na rede regular de ensino. A lei assegura ainda, dentre outros itens, professores capacitados e especializados; formação continuada; flexibilizações e adaptações curriculares.

Nesse contexto a escola inclusiva deve ter objetivos bem definidos e acreditar que todos os alunos possam aprender, respeitando as diferenças. A escola deve oportunizar recursos necessários para que a criança aprenda e não apenas colocar o aluno na sala de aula e esperar que ele aprenda por meio de seus colegas da mesma idade. Como afirma Santos e Araújo (2011, apud RANGEL, 2011, p.126): “A escola inclusiva deve possibilitar um espaço verdadeiramente democrático, garantindo condições objetivas de permanência que se distinguem pela inclusão multidimensionada e não pela mera inserção física, para além do simples acesso[...]”.

Assim, volta-se ao tema da formação docente continuada, destacando as salas de recursos multifuncionais que, quando utilizada por educadores capacitados, tornam-se um apoio fundamental para o processo de inclusão nas salas regulares. Ressaltando que não só nas salas de recursos devem ser aplicadas as TAs, pois segundo Emer (2011, p.85) “[...] acreditamos que realmente seja também papel do professor articular a inclusão do seu aluno em todo o contexto escolar.” Desse modo, o empenho do professor passa a ser fundamental para o processo de inclusão.

O Plano Nacional de Educação, no que se refere à educação especial, enfatiza que “[...] não há como ter uma escola regular eficaz quanto ao desenvolvimento e aprendizagem dos educandos especiais, sem que seus professores, demais técnicos, pessoal administrativo e auxiliar seja preparado para atendê-los adequadamente". E "As classes especiais [...] precisam contar com professores especializados e materiais pedagógicos adequados”. Confirmando assim que a inclusão não depende somente do professor, mas também do meio em que o aluno está inserido, tanto na escola quanto na comunidade.

Com base na Constituição da República Federativa do Brasil (1988), artigo 205, ao enfatizar que "[...] a educação, direito de todos, é dever do estado e da família”, pode-se afirmar que a família tem um papel de fundamental importância nesse processo de inclusão, pois são eles que escolhem se o aluno irá para a escola regular ou não, oportunizando os ambientes de inclusão.

\section{PROCEDIMENTOS METODOLÓGICOS}

De acordo com o objetivo apresentado nessa investigação utilizou-se uma pesquisa exploratória, que segundo Gil (2007) é o estudo aprofundado de um tema escolhido para familiarizar-se com a investigação. A pesquisa ocorreu numa escolinha de educação infantil localizada no município de Caxias do Sul, no período de seis meses com encontros de formação que concentravam todos os professores da escola para formação geral referente à temática discutida nessa pesquisa e depois com encontros de formação e acompanhamento específico com a professora que possuía em sua turma um aluno com Síndrome de Down.

Essa pesquisa apresentou uma abordagem qualitativa, uma vez que, busca descrever comportamentos de variáveis e situações. Roesch (2009) considera a pesquisa qualitativa apropriada para a avaliação formativa, quando se trata de melhorar ou aperfeiçoar a efetividade de um programa ou plano.

Quanto ao procedimento, foi utilizado o estudo de caso, que segundo Cervo e Bervian (2002), “[...] é a pesquisa sobre um determinado indivíduo, família, grupo ou comunidade que 
seja representativo do seu universo, para examinar aspectos variáveis de sua vida”. Para Gil (2007), o estudo de caso tem como propósito descrever a situação do contexto em que está sendo realizada determinada investigação.

Para a técnica de coleta de dados foi utilizada a Observação Participante, que segundo Marconi e Lakatos (1999), é definida pela participação real do pesquisador, não consistindo somente em ver e ouvir, mas também em examinar fatos ou fenômenos que se deseja estudar.

Pelo fato de a pesquisa possuir abordagem qualitativa, a interpretação dos dados será feita por meio da análise de conteúdo. Esse método, segundo Roesch (1999), usa uma série de procedimentos para levantar considerações a partir de um texto. Os dados coletados nessa investigação dividem-se em três categorias:
a) Formação docente sobre as TICs e TAs
b) Aplicação da Tecnologia Assistiva; e
c) Processo prático de Inclusão.

\section{APRESENTAÇÃO E ANÁLISE DOS RESULTADOS}

Após um estudo aprofundado sobre os temas em questão realizaram-se dois encontros de formação de professores, numa escola particular de educação infantil, visando informar e também observar a percepção dos professores com relação às Tecnologias de Informação (TICs) e a Tecnologia Assistiva (TA). Com essa prática, divide-se a apresentação e análise dos resultados em três categorias. As falas das professoras aqui citadas serão identificadas pela letra $\mathrm{P}$ e sua ordem numérica e quando referido aos alunos, pela letra $\mathrm{A}$ e sua ordem numérica. Primeira categoria:

a) Formação docente sobre as TICs e TAs;

Nessa categoria a pesquisa foi organizada em grupo de seis professoras, com formação no curso de pedagogia e magistério, algumas em andamento, no qual se apresenta a utilização das TICs e TAs nas práticas pedagógicas no contexto escolar.

Referindo-se as TICs percebe-se que as professoras estão atualizadas quanto aos recursos tecnológicos, porém, não preparadas para usá-los em sala de aula, pois além de terem resistência, preferindo o método convencional, tem dificuldade em transmitir o conhecimento por meio do uso da tecnologia.

Observando a geração de hoje, a maioria das pessoas percebe que não temos como educar os alunos da mesma forma que nós professores fomos educados, apenas com o quadro negro e o giz, porém, essa mudança ainda está longe de ocorrer legitimamente, pois como relata $\mathrm{P} 1$, com relação ao uso da tecnologia em sala de aula, "o professor não sabe passar o conceito e os alunos acabam levando na brincadeira".

Já P2, ao realizar um curso sobre Tecnologia de Informação, em uma escola particular, relata: "a professora quando foi usar a lousa digital, ela não conseguiu demonstrar pelo simples fato de não saber como utilizar, e ela tinha uma estatura baixa que nem alcançava, foi até chato, pois causou um certo mal estar na turma”.

Permanecemos no impasse entre as escolas que não tem recursos tecnológicos e as escolas que tem uma boa estrutura, porém, não há o interesse para a sua correta utilização. Cabe alocar a fala da P1, ao relatar: "na escola que estudo tem um laboratório de informática com as mais novas tecnologias, e até a poucos dias ninguém utilizava a lousa digital, mas recentemente um professor começou a usar em quase todas as aulas e de repente todos queriam usar". Com base nesse relato pode-se dizer que há sim, um incentivo por parte dos colegas, seja por interesse ou mesmo pela concorrência.

No que se refere à utilização das TICs na educação infantil, relatamos que é um recurso bem deficitário, pois as professoras fazem a associação de tecnologia com uso do computador pelo aluno. Por meio desse encontro de formação elas puderam perceber que na 
educação infantil pode-se trabalhar de diversas formas com o uso das tecnologias. Apresentou-se um projeto de utilização da máquina digital para tirar fotos da turma e, a partir dessas fotos montarem um quebra-cabeça e um jogo de memória, mostrando que não se restringe apenas ao momento do uso da tecnologia, e sim sua aplicação posteriormente para outras atividades. As professoras apresentaram muito interesse pelos sites como "recreio" e "turma da mônica", que além de trabalhar online, podem coletar ideias de projetos e brincadeiras para realizar em outro momento com os alunos.

Quanto a TA, apenas uma professora já tinha ouvido essa expressão. As professoras tem consciência de que todas as pessoas com algum tipo de deficiência podem ser incluídas na escola regular, porém, ainda acreditam ser uma realidade distante, que até pode acontecer nas outras escolas, mas não na escola em que trabalham.

Ao explicar os tipos de deficiências e apresentar algumas imagens de alunos, cada um com suas necessidades especiais, as professoras demonstraram resistência e até um certo preconceito diante desses casos. Percebe-se que ainda há uma cultura muito forte sobre um olhar diferente às PNEEs.

$\mathrm{Na}$ medida em que se mostraram exemplos de recursos e utensílios de acessibilidade, que as professoras puderam perceber que pequenos ajustes poderiam tornar possíveis ou melhorar o acesso a determinadas atividades, foi-se despertando o interesse pelo assunto e o sentimento de que sempre podemos fazer mais.

Perceberam também que na maioria dos exemplos apresentados foram utilizados materiais simples e de baixo custo, tornando um recurso fácil e que pode ser confeccionado por qualquer pessoa, desde que tenha a informação necessária.

Com exemplos de utilidade diária, como o contentor de alimentos e as adaptações com velcro nas escovas de dente, cabe ressaltar a fala da P3, que comenta: "aqui na educação infantil ainda quando eles são bem pequenos já podemos começar a estimulá-los a se alimentar, escovar os dentes, assim eles também vão se sentidos mais independentes”.

Essa aceitação pode-se observar também na fala da P6, que em relação a comunicação alternativa, comenta: "já vou pensar pra fazer com o aluno A1, não só nas atividades, mas na hora das refeições, no parque..."

Analisando essas falas, percebe-se que é possível sim, criar condições e recursos que possibilitem o acesso e melhore o desempenho das PNEEs, mas para isso, voltamos no tema formação de professores, pois são eles que irão identificar as necessidades de cada aluno e saberão a melhor forma de auxiliá-los.

No final do encontro uma professora relata um caso que aconteceu em uma escola particular de educação infantil na qual havia trabalhado anteriormente. P4: "começou o A2 na escola, ele tinha um atraso na coordenação motora, ele não caminhava, só se arrastava, não comia sozinho, se engasgava e babava bastante, a diretora levou ele até minha sala, me disse o que ele tinha e que eu deveria dar uma atenção especial para ele, tudo bem, só que eu tinha mais oito alunos e eu simplesmente não sabia como agir, pois eu precisava dar atenção à ele, sem deixar de atender os outros. Sem falar que ele não acompanhava a turma, é claro, mas eu não sabia como ajudar no seu desenvolvimento, não recebi auxílio de ninguém, eu nem sabia o que era Tecnologia Assistiva, hoje que eu estou vendo".

Com esse relato percebe-se que em muitos casos nem as escolas e nem os professores estão preparados para incluir um aluno com deficiência, mas há também o interesse em aprender, como se observa com a realização desse curso de formação, no qual mesmo sendo um assunto novo, torna-se uma nova forma de educar e também de aprender.

b) Aplicação da Tecnologia Assistiva (TA)

Para a aplicação da TA realizou-se um segundo encontro de formação, nesse momento apenas com a professora intitulada P6, na qual possui um aluno com necessidades especiais em sua turma, o A1, que tem Síndrome de Down. 
Ao estudar a deficiência e suas características observou-se que os alunos com Síndrome de Down possui um forte reconhecimento visual, fator este que facilita seu aprendizado diante da utilização de materiais de apoio visual, como por exemplo, figuras, fotos e objetos. Como afirma no Folheto da Down's Syndrome Association ${ }^{1}$, “[...] as crianças com Síndrome de Down têm fortes habilidades de aprendizagem visual, mas não são bons aprendizes auditivos. Sempre que possível eles necessitam de apoio visual e concreto e materiais práticos para reforçar as informações auditivas”.

Destaca-se ainda que não há problemas de comportamento característicos de crianças com Síndrome de Down, porém, seu comportamento está relacionado a seu nível de desenvolvimento. Sendo assim, podem ser desencadeados em algumas situações aparentemente banais. Por exemplo, eles podem se sentir frustrados ou ansiosos com mais facilidades. Uma questão particular dos problemas de comportamento são as estratégias para escapar das tarefas, comprometendo assim, o progresso de seu aprendizado. Alguns alunos usam comportamentos antissociais para distrair a atenção dos adultos e escapar do trabalho, e aceitam fazer tarefas que exigem pouco de sua capacidade cognitiva.

Com base nessas constatações e analisando as mesmas características presentes no A1, optou-se por utilizar a comunicação alternativa para auxiliar o aluno. Foram elaboradas cartas enigmáticas, pranchas de comunicação e álbum de comunicação. Dos recursos utilizados, a prancha de comunicação não despertou interesse do A1, não teve interação. $O$ álbum de comunicação já foi bem recebido, foi elaborado com figuras de alimentos, no qual o aluno reconheceu todas as figuras, elencou os alimentos que mais gostava e também os que aceitavam na escola. As cartas enigmáticas também foram bem aceitas, mas nesse recurso pode-se perceber claramente que o aluno despertou interesse apenas nos assuntos que ele gostava e que realmente lhe eram interessante naquele momento.

Dentre os temas utilizados cabe destacar três cartas enigmáticas, a primeira com possíveis atividades de rotina realizadas pelo A1, desde a manhã até a noite, contudo não teve uma receptividade muito boa, ele não fez associação do tempo, apenas escolheu os itens que gostava de realizar, como por exemplo, assistir TV, brincar no parque e alguns alimentos favoritos. A segunda carta continha atividades realizadas no parque da escola, tanto brincadeiras livres, quanto atividade de educação física orientada, esse item chamou-lhe bastante atenção, atendendo assim, nossa expectativa, pois sabíamos que ele adorava ir para o pátio. Na terceira carta aproveitamos a proximidade do Natal e elaboramos figuras de possíveis presentes que ele gostaria de ganhar, uma vez que, anteriormente haviam feito uma cartinha para o papai noel. Também foi bem recebida, chamando bastante atenção para a figura do papai noel.

Pode-se constatar que para os alunos com Síndrome de Down é de grande relevância a associação visual, pois a repetição ajuda a gravar a informação, por exemplo, se o professor falar de uma casa, apontar para uma, se falar de um cachorro, mostrar um. Lembrando que deve-se respeitar as diferenças de cada aluno e oportunizar os recursos necessários para que a criança aprenda, considerando o seu nível de desenvolvimento e não a idade cronológica da criança.

Como já falado anteriormente, sobre a elaboração de estratégias para desviar-se do trabalho, observamos que o A1, dependendo da atividade proposta, quando esta não lhe interessa, cria sim estratégias para desviar a atenção da professora e para não realizar o trabalho proposto. Nesse caso é importante que a professora esteja atenta e consiga identificar quando o aluno apresenta um comportamento imaturo, ou seja, não consegue desempenhar a

1 Informação retirada do Folheto da Down's Syndrome Association, produzido por Sandy Alton, e distribuído pelo Ministério da educação britânico, tradução Patricia Almeida. Versão original em inglês no link: http://downs-syndrome.org.uk/pdfs/DSA\%20A4\%2012pp\%20primary.pdf 
atividade, ou quando demonstra um comportamento deliberado, resultando em "não vou fazer”.

c) Processo Prático de Inclusão

Para Evangelista e Freire (2011), no momento em que se privilegiam os conhecimentos de todos enquanto sujeitos do saber, o processo de aprendizagem se transforma em um movimento de criação e não mais de repetição. Dessa forma todos os profissionais envolvidos no universo escolar contribuem para a construção de uma escola mais incluente.

Sendo assim, cabe ressaltar que não só o aluno deve ser incluído, mas também o professor, a sociedade e a escola, esta não só em infraestrutura, como também em recursos e materiais pedagógicos.

Na questão de acessibilidade a P5 comenta uma cena presenciada com relação ao transporte coletivo: "havia um rapaz cadeirante na parada e quando o ônibus adaptado parou, os operadores não conseguiram utilizar a rampa de acesso, o rapaz simplesmente teve de esperar pelo próximo ônibus”.

Com base nessa constatação voltamos a falar da formação, no qual nada adianta possuir os recursos se não temos pessoas capacitadas para operá-los. Ressaltando que cabe também às pessoas se conscientizarem da importância dessa formação.

A professora que conhecia a TA, comenta que participou de um processo de seleção em um órgão público para ser monitora, e nos relata conforme fala abaixo.

P3: "fiz a inscrição e me chamaram para participar de um curso preparatório de três dias com mais de cem pessoas, eu fiz o curso, mas depois fiquei com medo de atuar, pois percebi que o monitor tem que ter um olhar muito perceptivo sobre aquele aluno, para ver exatamente o que ele precisa, e não me sentia preparada apenas com esse curso. Depois de um tempo eles me chamaram e simplesmente me deram o nome do colégio e o endereço que eu iria trabalhar, sem informar qual a deficiência e as necessidades do aluno, senti a sensação que iria ser "jogada” na escola assim como o aluno com deficiência e optei por não ir. Até porque, percebo que dependendo do aluno não temos condições de auxiliá-lo, por exemplo, se for um aluno que use sonda, vai precisar saber de enfermagem, e se precisar levar no banheiro e for um adolescente, não tenho suporte físico para carregá-lo."

Analisando essa fala, a P4, com base no seu relato anterior, complementa: "foi mais ou menos o que aconteceu comigo, só que eu não era monitora e sim a professora, eu não sabia as reais necessidades do A2 e a escola não tinha recursos nem material diferenciado para atendê-lo. Era bem complicado pois eu não tinha como dar uma atividade exclusiva para ele sem deixar de lado os meus outros alunos”.

Nesse contexto percebe-se também o processo de inclusão com relação aos colegas de turma. Na educação infantil, os colegas demonstram-se bem atenciosos e solícitos com relação ao colega com necessidades especiais, eles sabem que ele é especial, mas o respeitam e o tratam sem diferenças. Ressaltando que o A1 tem Síndrome de Down, e frequenta a escola pesquisada.

Confirmando as falas anteriores, a P1 reforça que não só o professor, mas também a escola devem promover o acesso a esse aluno, como nos fala: "na escola que eu estudo tem um cadeirante e não tem rampa, nem o banheiro é adaptado e na sala de aula a cadeira dele não entra na classe. Não tem monitor, é a mãe dele que o ajuda e carrega ele quando ele precisa sair”. Nesse caso percebe-se também a importância da família nesse processo, mas ao mesmo tempo se questiona, é esse o exemplo de inclusão?

Analisando esse contexto percebemos a difícil realidade que encontramos hoje, que de um lado estão às políticas públicas no processo de inclusão e de outro os alunos que frequentam escolas que dizem ser inclusivas, quando na verdade esse processo de inclusão acaba os excluindo por falta de preparo e condições necessárias. 


\section{CONSIDERAÇÕES FINAIS}

Por muito tempo as pessoas com deficiência eram excluídas dos lugares públicos, cabia a elas a responsabilidade de se adequar à sociedade. Hoje, cabe à sociedade adaptar-se para respeitar e acolher as diferenças e promover condições de acesso a todos os espaços da sociedade.

Sendo assim as escolas, os professores e a comunidade têm de estar preparados para receber esses alunos e oportunizar as condições necessárias para seu desenvolvimento.

Embora a inclusão de pessoas com deficiência na escola regular seja um fato inquestionável, no decorrer desse trabalho percebe-se ainda um olhar muito resistente ao aluno com necessidades especiais. Nota-se também a falta de conhecimento sobre o assunto, considerando que a maioria das professoras nunca tinha ouvido falar em Tecnologia Assistiva.

Por meio dos encontros de formação, no qual, podem-se passar informações e exemplos de utilização da TA nos alunos com deficiência, observa-se que há o interesse por partes das professoras em ajudar seus alunos especiais a torná-los mais independentes e confiantes.

De acordo com as falas apresentadas, observa-se que existe a consciência de que para efetivar realmente o processo de inclusão é necessário que não só o aluno com deficiência seja incluído, mas que a escola esteja preparada, não só com a estrutura física, mas em materiais e recursos pedagógicos adequados. É preciso também que o professor esteja disposto a receber esse aluno com as suas particularidades, e busque os recursos de TA necessários, que em muitas vezes, estão a seu alcance.

Observa-se que ainda há muito que se fazer para que o aluno com deficiência seja realmente incluído na escola regular, contudo percebemos o avanço da tecnologia cada vez mais rápido, e com ela a necessidade de os professores se inserirem nesse novo contexto, trazendo o uso das TICs nas práticas pedagógicas e os novos recursos de acessibilidade por meio das TAs, para sua correta aplicação em alunos com necessidades especiais, respeitando as diferenças e a realidade de todos os envolvidos.

\section{REFERÊNCIAS BIBLIOGRÁFICAS}

ALTON, Sandy. Folheto da Down's Syndrome Association, distribuído pelo Ministério da educação britânico, tradução Patricia Almeida. Disponível no endereço eletrônico: www.portalsindromededown.com/.../incluindo_alunos_com_sd. Acesso em: 16/10/2012. Versão original em inglês no link: http://downssyndrome.org.uk/pdfs/DSA\%20A4\%2012pp\%20primary.pdf

BERSCH, Rita de Cássia Reckziegel. Introdução à tecnologia assistiva. CEDI - Centro Especializado em Desenvolvimento Infantil. Porto Alegre, RS: 2008.

BRASIL, Ministério da Educação. Plano nacional de educação. Lei nº 10.172, de 9 de janeiro de 2011. Disponível no endereço eletrônico:

http://portal.mec.gov.br/arquivos/pdf/pne.pdf. Acessado dia 16/10/2011.

CERVO, Amado L., BERVIAN, Pedro A. Metodologia científica. 5. ed. São Paulo: Prentice Hall, 2002.

Constituição da República Federativa do Brasil (1988). 
DEMO, Pedro. Universidade, aprendizagem e avaliação: horizontes reconstrutivos. POA, RS: Mediação, 2004.

EMER, Simone de Oliveira. Inclusão escolar: formação docente para o uso das TICs aplicada como tecnologia assistiva na sala de recurso multifuncional e a sala de aula. Dissertação (Mestrado) -- Universidade Federal do Rio Grande do Sul, Faculdade de Educação, Programa de Pós-Graduação em Educação, Porto Alegre, BR-RS, 2011.

EVANGELISTA, Marcia Nico; FREIRE, Wendel. Supervisão e narrativa no cotidiano escolar. In: Rangel, Mary e Freire, Wendel (org.). Supervisão escolar: avanços de conceitos e processos. Rio de Janeiro: Wak, 2011.

GIL, Antônio Carlos. Como elaborar projetos de pesquisa. São Paulo: Atlas, 2007.

HOGETOP, L. e SANTAROSA, L. M. C. Tecnologias assistivas: viabilizando a acessibilidade ao potencial individual. Informática Na Educação: teoria \& prática, Porto Alegre: v. 5, n. 2, p.103-118, nov. 2002.

INSTITUTO DE TECNOLOGIA SOCIAL. Tecnologia assistiva nas escolas:

Recursos básicos de acessibilidade sócio-digital para pessoas com deficiência. Ed Microsoft. 2008.

LIBÂNEO, Jóse Carlos. Organização e gestão da escola. Teoria e prática. 3 ed. Goiania: Alternativa, 2001.

MARCONI, Maria de Andrade \& LAKATOS, Eva Maria. Técnicas de pesquisa:

planejamento e execução de pesquisas, amostragens e técnicas de pesquisas, elaboração, análise e interpretação de dados. São Paulo: Atlas, 1999.

RANGEL, Mary \& FREIRE, Wendel. Supervisão escolar: avanços de conceitos e processos. Rio de Janeiro: Wak, 2011.

ROESCH, Sylvia Maria Azevedo. Projetos de estagio e pesquisa em administração: guia prático para estágios, trabalhos de conclusão, dissertações e estudos de caso. 2. ed. São Paulo: Atlas, 1999.

SIQUEIRA, Ethevaldo (org). Tecnologias que mudam a nossa vida. São Paulo: Saraiva, 2007.

VYGOTSKY, L. S. et al. Linguagem, desenvolvimento e aprendizagem. São Paulo: Ícone, 1988. 